\title{
Breves encuentros: el cortometraje como esencia del cine
}

\section{Brief encounters: short films as the essence of filmmaking}

Fechas | En edición: 08/09/2020 - Publicación final: 01/01/2021

\section{Nadia McGOWAN}

Universidad Internacional de La Rioja. España. nadia.mcgowan@unir.net

\section{Nuevos márgenes del cortometraje}

E. C. GARCÍA-FERNÁNDEZ; C. MANZANO-ESPONOA y L. DELTELLESCOLAR.

Madrid: Fragua, 2020.

244 páginas

ISBN: 978-84-7074-864-6

Ebook: sin edición electrónica hasta la fecha.

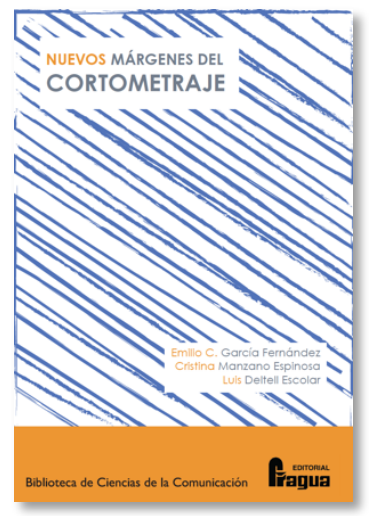

\section{Resumen}

Nuevos márgenes del cortometraje es una investigación multidisciplinar y con enfoques diversos sobre la situación del cortometraje en el panorama audiovisual mundial. Los tres autores abordan desde tres líneas distintas de la industria cinematográfica la creación en el formato breve. Sus conclusiones indican que es un estímulo para la animación, el documental y nuevas formas de publicidad como el branded content.

\section{Palabras clave}

Animación; branded content; cine español; cortometraje; ensayo audiovisual.

\section{Abstract}

New margins of the short film is a multidisciplinary study with different perspectives on the situation of short films in the global audio-visual environment. The three authors address the creation of films in short format from three different filmmaking industry perspectives. Their conclusions suggest that it encourages animation, documentaries and new forms of advertising such as branded content.

\section{Keywords}

Animation; branded content; Spanish cinema; short film; audio-visual essay 
Nada más concluida la Segunda Guerra Mundial, durante el corto período liberal que gozaron los cines inglés y estadounidense antes de la llegada del macartismo, el director británico David Lean filmó uno de los títulos más escandalosos de su filmografía: Breve encuentro (Brief Encounters, 1945). En este largometraje, como se sabe, una mujer y un hombre, ambos casados, mantenían una relación amorosa esporádica y corta. El romance concluía, Deus ex machina, con el hombre viajando a la India con su familia. Para los dos protagonistas esos breves momentos de encuentro resultaron claves en su vida; en ellos parecía concentrarse todo lo mejor de la pasión. En el libro Nuevos márgenes del cortometraje circula una hipótesis similar: el formato breve del cine no es solo una forma menor, sino que precisamente su escasa duración permite mayor experimentación ya sea en la animación, el cine documental o las nuevas formas de publicidad como el branded content.

El trabajo se enmarca dentro de la línea de investigación de ESCINE, grupo complutense de estudios cinematográficos y lo escriben tres autores distintos: Cristina Manzano Espinosa que indaga sobre el cine de animación; Luis Deltell Escolar que analiza el cine documental en formato breve y, por último, Emilio C. García Fernández, quien aborda las nuevas maneras de publicidad.

Los tres investigadores plantean que gracias a que los cortometrajes son productos son de escasa duración (y de menor presupuesto), han permitido que los cineastas realicen nuevas aportaciones y nuevos hallazgos. Aunque el cortometraje es un camino de aprendizaje no es, para los autores, únicamente un formato de aprendizaje, sino más bien un formato de experimentación. Es inevitable acordarse de la célebre cita popularizada por el arquitecto alemán Mies Van der Rohe: menos es más.

El primero de los textos lo compone Manzano Espinosa y se titula "El cortometraje de animación como reflejo de la sociedad contemporánea". Se trata de un pormenorizado estudio de la animación en este breve formato. La autora no solo hace un dibujo de la situación mundial del cortometraje, algo que resulta interesante y novedoso, sino que, además, logra encontrar las relaciones entre las sociedades y los cineastas. La autora explica cómo hay ciertos temas recurrentes y frecuentes en los cortometrajes: la identidad, el acoso escolar (bullying) y la situación desigual de la mujer con respeto al hombre dentro de la sociedad. Estos tres temas muestran un enfoque completamente nuevo y diferenciado al modelo tradicional que se había dado en la animación (especialmente si se compara con la más comercial de Hollywood de hace décadas). Es este uno de los puntos más interesantes de su texto pues si bien el tema recurrente de "lecciones de la vida" podría ser una constante de la historia del cine, cobra en el cortometraje actual un valor especial aquí, pues estos aprendizajes vitales en nada se parecen a las moralejas precedentes.

Un aspecto clave en el texto de Manzano Espinosa, que se repetirá en el siguiente capítulo, es el indagar sobre la técnica: sus cambios, sus modificaciones y las mutaciones que han generado. Por supuesto, el dato más revelador será el abaratamiento de los costes de producción pero, también, la gran libertad que ha dado a los cineastas más creativos. Las técnicas de animación han experimentado una modificación tan grande que podríamos hablar abiertamente de una mutación en el género.

El siguiente capítulo, escrito por Luis Deltell Escolar, se titula: "Breve cartografía del cortometraje documental en España durante las dos primeras décadas del siglo XXl". El autor -que además de docente es cineasta- aborda el panorama del cortometraje de no ficción y experimental en España. Se trata ya no de un área al margen de la industria del cine, sino del margen de los márgenes del audiovisual. Como defiende Deltell, este espacio ha quedado como refugio o lugar para la mayor experimentación y las propuestas más singulares del cine español. Aunque se trata de películas de un mínimo (o nulo) impacto comercial y económico, al ser tan baratas y tan sencillas en su producción han logrado crear todo un entramado de festivales, plataformas y sistemas de distribución y exhibición paralelos a los grandes cauces.

El autor menciona cómo la no ficción en España —siguiendo algo que parece acontecer en toda Europa- está viviendo uno de sus mejores momentos. Varias son las líneas que han generado esta nueva situación el cine de la llamada "escritura del yo" o ensayo audiovisual y los documentales creativos. Ambas líneas, como indica Deltell, tiene diversas escuelas y canales en el país. Es interesante mostrar cómo las instituciones, entre ellos la Academia de Cine de España, parecen preocuparse cada día más por este género y apoyan de forma consciente y proactiva al cortometraje documental.

El último de los capítulos lo firma Emilio C. García Fernández y trata del uso de los cortometrajes desde una perspectiva publicitaria. El catedrático de Historia del Cine Español de la Universidad Complutense de Madrid -recientemente jubilado- detalla de forma cuidada y cuidadosa los casos más importantes de las películas breves financiadas por compañías siguiendo las técnicas del branded content y, también, los criterios del storytelling. 
García Fernández presenta una hipótesis muy interesante y es que la nueva publicidad busca desesperadamente contar una experiencia o una historia en vez de vender directamente el producto. Para lograr este objetivo, el cine y muy especialmente el cortometraje audiovisual tienen mucho que aportar, pues llevan desde Edison y los hermanos Lumière más de un siglo narrando y difundiendo emociones de forma concentrada.

García Fernández explica cómo en este caso los directores que parecían dedicados exclusivamente al largometraje o las series de televisión de gran envergadura vuelven al cortometraje. Es cierto que en muchas ocasiones parece que se trata de cuestión pecuniaria, pero en otras las propuestas son realmente atractivas y fílmicamente interesantes. Por ello, el autor plantea que el uso de la publicidad puede ser una estrategia útil para ambos sectores: cinematografía y publicidad.

Un dato nada menor es la presencia de directoras de cortometraje en este libro. En los tres capítulos se menciona un porcentaje significativo de mujeres cineastas. Desconocemos si es una inclusión buscada o simplemente sucede por el calidad obvia y demostrada de los trabajos que se citan. Cuando se habla de Breve encuentro, el film que da título a esta reseña, se dice que era un film escandaloso. Resulta curioso que una de las cosas que aterraron a los censores - fuera ya del obvio adulterio- es que la mujer protagonista fuera sola a ver una película al cine. La soledad y la independencia de una espectadora causaba pudor a los censores. En Nuevos márgenes del cortometraje se habla, sin hacer ninguna soflama, de un mundo lleno de mujeres cineastas independientes y de gran talento. No solo pueden ir solas al cine, sino que, además, filman las películas. 